\title{
Fault Detection System of Underground Cables
}

\author{
Himanshu Katara
}

\begin{abstract}
This paper suggests a fault detection system of underground cables by making the use of microcontroller and internet of things (IOT). After detecting the location of fault in the underground cable the microcontroller alerts the user remotely through the IOT. The occurrence of fault up to a predefined distance can be investigated through this proposed system. The display unit is attached to the system for displaying the electrical parameter such as voltage, current and also the distance at which fault occurs. The fault detector measures the current and voltage of underground cable and if there occurs the high difference between voltages and current of two terminals of fault detector then the detector will alert the user remotely without going close to the cable.
\end{abstract}

Keywords- Internet of things (IOT), microcontroller, fault detector, underground cables.

\section{INTRODUCTION}

The core purpose of the electricity transmission system is to move electric power from the generating unit to different load centers [1]. Instead of transferring electrical power from overhead transmission line underground cables are more preferable since underground cables are not affected by climatic condition like earthquake, lightning, heavy rain, winds, snow fall etc. The formation of cracks or joins in the cable definitely disturb the power transfer from generating station to load [2], [3]. Therefore, it is important to find out the exact location of occurrence of fault [4]. So, for this the world is moving towards digitalization to find the solution of such problem. In most of the urban areas the underground power cables are most commonly used since it does not require much area. It is buried beneath the earth and promote clean environment [5]. Although some sort of fault is involved, at that time it is difficult to do the repair process associated with that particular cable as the exact location where a fault is located is not known. In the underground cables basically two types of fault arise first is open circuit fault. These types of fault occur due to the breaking of conductor, cracks or disjoints of conductor completely. Second is short circuit fault, these types of fault occur due to the failure of insulator or due to the contact of two or more conductor together. The short circuit fault is of two types one is symmetrical fault and other is unsymmetrical fault [6]. The symmetrical fault occurs due to the short circuit of all three phase together whereas unsymmetrical fault occurs due to the short circuit of any one phase or two phases together out of three phases [7].

\section{SYSTEM DESCRIPTION}

In this proposed fault detector, the dc voltage is supplied to the feeder through the number of series resistor. If there is a short circuit or open circuit is present in the conductor, the

Revised Manuscript Received on 14 September, 2019.

Himanshu Katara, Department of Electronics Engineering, Sanskriti University, Uttar Pradesh, India.(Email: sanpubip@gmail.com) current flowing through the circuit will change its magnitude which is detected by the cable fault detector [8]. For operating the microcontroller and other electronic device installed in the proposed system will be work with the help of ADC converter. The ADC will convert the ac voltage into dc voltage for the processing of microcontroller [9]. The detector will detect any type of underground fault up to two $\mathrm{km}$ and alert the user for the same wirelessly.

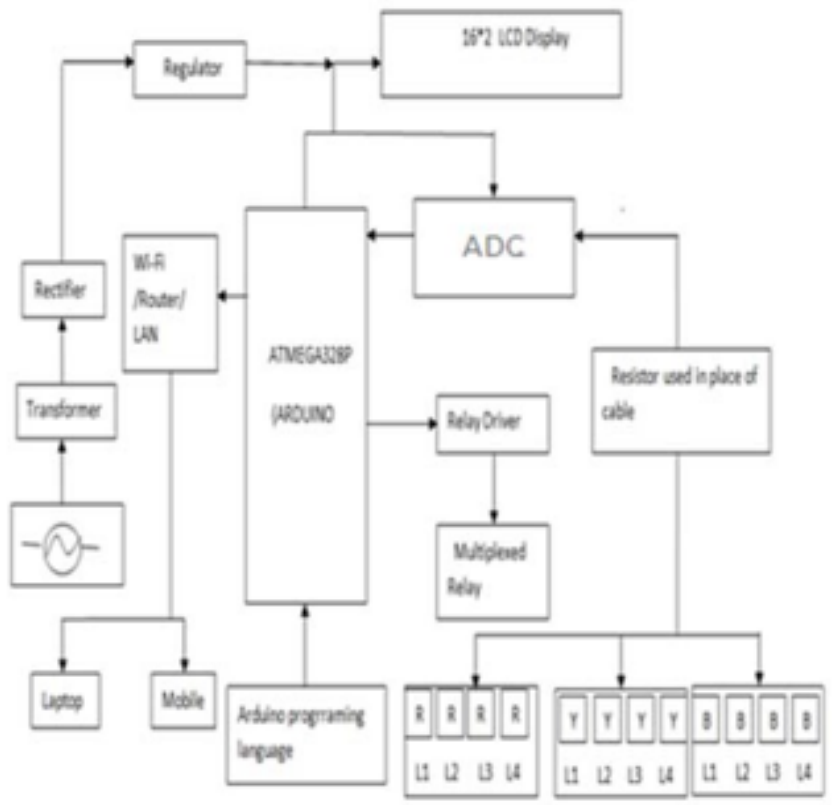

Fig. 1 Block Diagram of Proposed System

Fig. 1 shows the block diagram of fault detection system of underground cables. The basic goal of proposed model is to locate and detect the type of fault in the underground cable using microcontroller. Mainly it comprises of a stepdown transformer, a dc supply unit, rectifying unit, controlling unit, regulating unit and displaying unit. For the operation of proposed system, firstly the power is supplied to the step-down transformer which step down high voltage into low voltage [10]. Further, the low voltage is given to the rectifying unit, wherein the rectifying unit is a bridge rectifier. The rectifying unit convert low ac voltage into dc voltage. The dc voltage is then converted into fixed dc by the regulating unit. The sensor is placed to detect the changes in the voltage drop and notify the user for the same. 


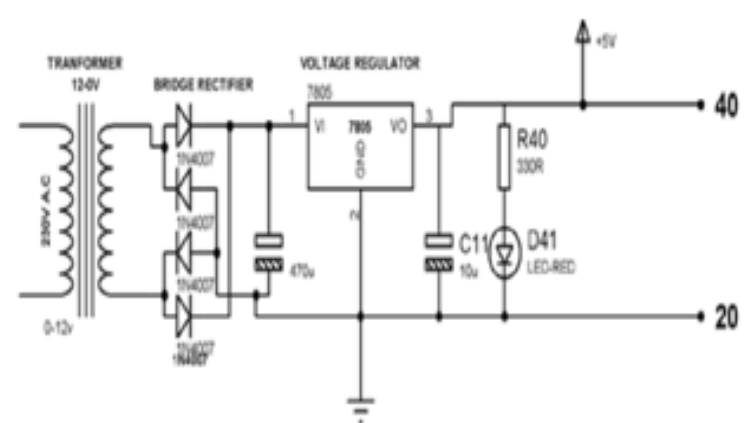

Fig. 2 Circuit diagram of Proposed System

The converting unit is a microcontroller that include analog to digital converter for converting analog signal of sensing unit and converting it into digital form for operating of microcontroller. The microcontroller does the processing for estimating the exact point at which fault occurs. It also operates rely for protecting the system from the affects of fault and provide protection to each phase. In the end, the displaying unit associated with microcontroller is used for determining the distance of fault in the underground cable and also the type of faults.

\section{RESULT}

Following result has been obtained by doing different case study. In case 1 if there is no fault in the underground cable then display unit will display line ok. In case 2 if there is any short circuit fault in any of the three line within the range of $2 \mathrm{~km}$ then the fault detector will alert the user through the display unit.

\section{Underground Cable Fault Detector}

LINE 1 LINE 2
TOKI LINE 3
IOKI

Case 1 (If there is no fault)

\section{Underground Cable Fault Detector}

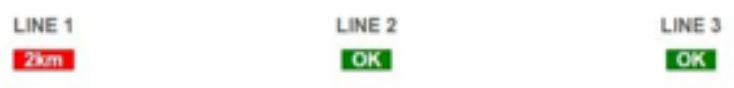

\section{Case 2 (if there is a fault at line 1 within $2 \mathrm{~km}$ )}

In case 3 if all the three lines have short circuit fault within $2 \mathrm{~km}$ then the display unit will alert the user by showing in the displaying unit.

\section{Underground Cable Fault Detector}

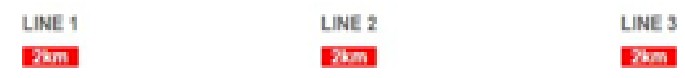

\section{Case 3 (if there is fault at all three cable within $2 \mathrm{~km}$ )}

\section{CONCLUSION}

This paper focus on the study of designed fault detection system for the underground cables. If there is any fault in any of the three line of underground cable then this detector is capable of detecting the short circuit fault within the range of $2 \mathrm{~km}$. The proposed system is cheap, human friendly and easy to operate. It eliminates the difficulty in detection of faults in underground fault. The microcontroller is installed in this system for assisting the detector to work smartly.

\section{REFERENCES}

1. C. F. Jensen, Online Location of Faults on AC Cables in Underground Transmission Systems. 2014.

2. T. S. Sidhu and Z. Xu, "Detection of incipient faults in distribution underground cables," IEEE Trans. Power Deliv., 2010.

3. T. S. Sidhu and Z. Xu, "Detection and classification of incipient faults in underground cables in distribution systems," in Canadian Conference on Electrical and Computer Engineering, 2009.

4. B. Kasztenny, I. Voloh, and C. G. Jones, "Detection of incipient faults in underground medium voltage cables," in 2009 Power Systems Conference: Advance Metering, Protection, Control, Communication, and Distributed Resources, PSC 2009, 2009.

5. C. Zhang, X. Kang, X. Ma, S. Jiang, and X. Qu, "On-line incipient faults detection in underground cables based on single-end sheath currents," in Asia-Pacific Power and Energy Engineering Conference, APPEEC, 2016.

6. C. V. N. S. P. P. Dr.A.Ratinam, "Fault Analysis of Underground Cable System with Magnetic Shield Using Finite Element Analysis,” Int. J. Sci. Res., 2015.

7. M.-S. Kalami, "Electric Power Cable Fault Recognition via combination of wavelet transform and optimized artificial neural network by using bees algorithm," Int. J. Mechatronics, Electr. Comput. Technol., 2014.

8. C. J. Yang, D. F. Hong, G. X. Ren, and Z. H. Zhao, "Cable installation simulation by using a multibody dynamic model," Multibody Syst. Dyn., 2013.

9. P. Ocłon et al., "The performance analysis of a new thermal backfill material for underground power cable system," Appl. Therm. Eng., 2016.

10. Nexans, "60-500 kV High Voltage Underground Power Cables XLPE Insulated Cables,” 2011. 